\title{
Relationship between Kt/N urea-based dialysis adequacy and nutritional status and their effect on the components of the quality of life in incident peritoneal dialysis patients
}

Jin-Bor Chen ${ }^{1 \dagger}$, King-Kwan Lam ${ }^{1+}$, Yu-Jen Su', Wen-Chin Lee ${ }^{1}$, Ben-Chung Cheng ${ }^{1}$, Chien-Chun Kuo', Chien-Hsing Wu', Eton Lin', Yi-Chun Wang ${ }^{1}$, Te-Chuan Chen ${ }^{1,2^{*}+}$ and Shang-Chih Liao ${ }^{1,2^{*}+}$

\begin{abstract}
Background: It is well known that the quality of life of patients with chronic kidney disease can be improved by dialysis. While previous studies have used retrospective designs and adhered to a standard target prescribed by clinical guidelines, our study prospectively investigates the association between the adequacy of peritoneal dialysis (PD) and measures of nutritional status on quality-of-life domains in a cohort of incident PD patients.
\end{abstract}

Methods: It was a prospective 6-month observational study. Eighty incident PD participants who were treated in a hospital-based PD center were enrolled. The period of enrollment was January 2009-June 2010; follow-up continued until December 2010. PD adequacy indices, including Kt/N urea, weekly Ccr (WCcr), measures of nutritional status (albumin, BMI), and nPCR were measured at 1 month and 6 months after PD initiation. SF-36 health survey questionnaires were used to measure the quality of life. The outcomes were used to measure the changes in the domains of the SF-36 after 6 months of PD therapy.

Results: Seventy-seven incident patients who underwent PD for 6 months were included in the study. The mean age was 47.3 years, and the male-to-female ratio was 38:39. A peritoneal $\mathrm{Kt} / \mathrm{N}$ urea value of 1.2 , which was also the baseline cutoff value, was found to have the highest influence on SF-36 domains. Patients with baseline peritoneal $\mathrm{Kt} / \mathrm{N}$ urea value of $<1.2$ showed improvement in the physical functioning and role limitation of physical functioning components after 6 months of PD. In contrast, patients with baseline peritoneal Kt/N urea values of $\geq 1.2$ showed remarkable improvement in the general health, physical functioning, role limitation caused by physical problems, and bodily pain components. However, the trend of improvement decreased in patients with baseline nPCR of $<1.2$. Baseline renal WCcr did not influence the improvement in the SF-36 domains.

Limitations: A small cohort and a short observation period.

Conclusions: The baseline level of peritoneal Kt/N urea affected the components of the quality of life after PD initiation. In contrast, a lower baseline nPCR level was associated with deterioration in the quality of life after PD therapy.

Keywords: Peritoneal dialysis, Quality of life, SF-36

\footnotetext{
* Correspondence: puppy@adm.cgmh.org.tw; shangchi@adm.cgmh.org.tw

${ }^{\dagger}$ Equal contributors

'Division of Nephrology, Kaohsiung Chang Gung Memorial Hospital and Chang Gung University College of Medicine, Kaohsiung, Taiwan

Division of Nephrology, Chang Gung Memorial Hospital, Kaohsiung, No. 123,

Ta Pei Road, Niao Sung District, Kaohsiung City, Taiwan
} 


\section{Background}

The concept of health-related quality of life (HRQoL) in patients with chronic kidney disease (CKD), including end-stage renal disease (ESRD), has evolved since the inception of renal replacement therapy, evolving from ensuring easy survival to achieving a sense of well-being [1]. Patients with CKD tend to show a reduction in their quality of life (QoL) because of the restrictions resulting from CKD treatment. Multiple factors, such as the presence of co-morbidities, can further reduce the QoL. Interventions aiming to improve the clinical condition and the QoL of these patients are of paramount importance, since the latter is directly associated with mortality. The association between the reduction of QoL and preventable and controllable factors including diabetes [2], old age [3], inadequacy of dialysis, inflammation and poor nutrition, is still unclear. In addition, studies have shown that dialysis initiation improves the QoL in ESRD patients [4-8]. However, the association between dialysis adequacy indices or nutritional parameters and QoL is inconsistent. These results may be inconsistent owing to the small sample of patients in those studies, non-ESRDspecific assessments, inadequate observation periods, or other factors.

Several validated, disease-specific HRQoL questionnaires can be used for the dialysis cohort, such as the World Health Organization Quality of Life Survey (WHOQOL), Short Form (SF)-36 health survey, the Kidney Disease Quality of Life (kDQOL), and the Choices Health Experiences Questionnaire (CHEQ). Patients with $\mathrm{Kt} / \mathrm{V}$ urea values above 2.0 undergoing peritoneal dialysis (PD) were found to have higher total SF-36 scores than patients with $\mathrm{Kt} / \mathrm{V}$ urea values below 2.0 [6], although some researchers argue that the correlation between $\mathrm{Kt} /$ $\mathrm{V}$ urea values and SF-36 scores is not significant [8]. There are only 2 validated native-language editions of questionnaires in Taiwan: the WHOQOL and the SF-36. In Taiwan, the SF-36 questionnaires have been used as a validation tool in a multi-center study comparing the QoL between PD and hemodialysis patients [9].

In this study, we used the SF-36 to assess the QoL in an incident cohort of PD patients. The purpose of the study was to investigate which components of the SF-36 could be improved after PD initiation. In addition, the influences of PD adequacy indices and nutritional status measures on the components of the SF-36 were explored.

\section{Methods}

Incident ESRD patients who consulted a PD institution at a medical center in southern Taiwan between January 2009 and June 2010 were enrolled in this prospective study. The following were the inclusion criteria: (1) new PD patients; (2) aged above 17 years; (3) able to express themselves; (4) no history of psychiatric disease; and (5) clinically stable with no evidence of chronic or acute infections, inflammatory disorders, malignancy, or antiinflammatory drug use 3 months prior to enrollment. The exclusion criteria were as follows: (1) aged below 17 years; (2) unable to receive PD therapy for three months after PD initiation; (3) unable to complete the questionnaires by themselves; (4) major clinical events requiring hospital admission; and (5) discontinuation of PD owing to kidney transplantation, technique failure, death, transfer to hemodialysis, or loss to follow-up. As per the study protocol requirement, all patients had completed at least 6 months of consecutive PD therapy, and 77 of 80 clinically stable patients (38 men and 39 women) were finally eligible. The mean age was 47.3 years. All the patients were dialyzed using commercially available dialysate $(\mathrm{pH}$ 5.2; Dianeal PD solution; Baxter, Singapore) containing $40 \mathrm{mmol} / \mathrm{L}$ lactate. Forty-five patients received continuous ambulatory PD (CAPD) therapy, with 4 exchanges every day. Thirty-two patients received automated PD (APD) therapy.

The QoL was measured using the Chinese version of the Short Form (SF)-36 health survey questionnaire (Taiwan Standard Version 1.0) - a generic self-report QoL instrument-comprising 36 items, which are assigned to the following 8 domains: general health, physical functioning, role limitation due to physical problems, bodily pain, mental health, social functioning, role limitation due to emotional problems, and vitality. The first 4 domains constitute the physical component scale, and the next 4 constitute the mental component scale. Higher scores indicate better QoL.

All the patients were asked to complete the SF-36 questionnaire prior to PD therapy as well as 6 months after PD initiation. A standard peritoneal equilibrium test (PET) was performed in the first month and then after 6 months after PD initiation. The clinical characteristics of all patients, including demographic and biochemical data, PD adequacy indices of renal and peritoneal $\mathrm{Kt} / \mathrm{V}$ urea and creatinine clearance (Ccr), and nutritional indices (serum albumin, normalized protein catabolic rate [nPCR]) were collected as baseline information at the beginning of the study. These data were collected again at 6 months for statistical analysis.

The protocol for the study was approved by the Committee on Human Research at Kaohsiung Chang Gung Memorial Hospital (CMRPG880091) and conducted in accordance with the Declaration of Helsinki. All participants signed an informed consent form before taking part in the study.

\section{Statistical analysis}

Using a general linear model, we determined an applicable $\mathrm{Kt} / \mathrm{V}$ value to determine the effect of $\mathrm{Kt} / \mathrm{V}$ on the 
QoL (Table 1). On the basis of the Kt/V value selected by us, the following patient characteristics were recorded, grouped, and compared using the MannWhitney test, Chi-square test, or likelihood ratio test: age; gender; clinical data including values for peritoneal urea $\mathrm{Kt} / \mathrm{V}$, residual renal urea $\mathrm{Kt} / \mathrm{V}$, total $\mathrm{Kt} / \mathrm{V}$, weekly peritoneal Ccr, weekly residual renal Ccr, total weekly Ccr, high-sensitivity C-reactive protein (hs-CRP), albumin, GPT, hemoglobin ( $\mathrm{Hb})$, and nPCR; and the 8 multiitem domains of the SF-36. Thus, age, peritoneal Kt/V, residual renal WCcr, and $\mathrm{nPCR}$ were regarded as independent variables for exploring the effect of PD therapy on SF-36 scores. Statistical analyses were performed using the IBM SPSS Statistics 19 (SPSS Inc. Chicago, IL) program.

\section{Results}

Association between the baseline peritoneal kt/V urea values and the scores of the SF-36 components

More components of the SF-36 were influenced by peritoneal $\mathrm{Kt} / \mathrm{V}$ values when the cutoff peritoneal $\mathrm{Kt} / \mathrm{V}$ value was set at 1.2. General health, physical functioning, role limitation due to physical problems, and bodily pain scores had significantly improved when the peritoneal $\mathrm{Kt} / \mathrm{V}$ value was above 1.2. In contrast, the scores for only the general health component improved when the peritoneal $\mathrm{Kt} / \mathrm{V}$ value was below 1.2 (Table 1 ).

\section{Stratification of the patients on the basis of peritoneal $\mathrm{kt} / \mathrm{V}$ urea and $\mathrm{nPCR}$ values}

The patients were stratified into 2 groups on the basis of baseline Kt/V urea values above or below 1.2. The peritoneal Kt/V urea, total Kt/V urea, and weekly peritoneal Ccr values (Table 2) were significantly different between both groups. When the patients were stratified according to an nPCR value above or below 1.2, those with $\mathrm{nPCR}$ values of $\geq 1.2$ had higher total $\mathrm{Kt} / \mathrm{V}$ urea and WCcr values than those with nPCR values of $<1.2$ (Table 3). The baseline
Table 2 Baseline patient characteristics and SF-36 domains stratified by peritoneal $\mathrm{Kt} / \mathrm{V}$ urea levels

\begin{tabular}{|c|c|c|c|}
\hline & \multicolumn{3}{|c|}{ Peritoneal Kt/V urea } \\
\hline & $<1.2(n=11)$ & $\geqq 1.2(n=66)$ & \\
\hline & Median (Range) & Median (Range) & $P$ \\
\hline Age (years) & $54.3(19.9-68.1)$ & $48.8(17.6-80.1)$ & 1 \\
\hline Gender, Male (n) & 5 & 33 & $0.780^{*}$ \\
\hline DM, n (\%) & $2(18.2)$ & $20(30.3)$ & $0.392^{\mathrm{a}}$ \\
\hline BMI & $20.1(14.4-28.2)$ & $20.5(16.4-35.2)$ & 0.760 \\
\hline $\begin{array}{l}\text { PD modality, } \\
\text { CAPD/APD (n) }\end{array}$ & $8 / 3$ & $34 / 32$ & $0.247^{*}$ \\
\hline $\mathrm{Hb}(\mathrm{g} / \mathrm{dL})$ & $8.9(3-13)$ & $8.9(6-12)$ & 0.708 \\
\hline Albumin (g/dL) & $3.6(2.3-4.2)$ & $3.6(2.4-4.9)$ & 0.86 \\
\hline GPT (U/L) & $12(4-41)$ & $15(3-458)$ & 0.676 \\
\hline $\mathrm{Cr}(\mathrm{mg} / \mathrm{dL})$ & $12.4(5.1-21.7)$ & $12(3.9-20.3)$ & 1 \\
\hline hs-CRP (mg/L) & $3.79(0.2-40.1)$ & $4.8(0.2-199)$ & 0.067 \\
\hline Peritoneal Kt/N urea & $1.01(0.7-1.2)$ & $1.44(1.2-2.3)$ & $<0.001$ \\
\hline Residual renal Kt/N urea & $0.79(0.2-4.1)$ & $0.54(0-2.1)$ & 0.111 \\
\hline Total Kt/N urea & $1.78(1.1-4.8)$ & $2.11(1.2-3.3)$ & 0.003 \\
\hline $\begin{array}{l}\text { Peritoneal WCcr L/week/ } \\
1.73 \mathrm{~m}^{2}\end{array}$ & $31.5(10.9-40.2)$ & $37.1(20.5-55.2)$ & $<0.001$ \\
\hline $\begin{array}{l}\text { Residual renal WCcr } \\
\mathrm{L} / \text { week } / 1.73 \mathrm{~m}^{2}\end{array}$ & $38.6(8.8-262.4)$ & $29.8(0-204.8)$ & 0.103 \\
\hline $\begin{array}{l}\text { Total WCcr } \\
\text { L/week/1.73m² }\end{array}$ & $68.2(44.9-348.4)$ & $72.7(31.4-226.7)$ & 0.58 \\
\hline $\mathrm{nPCR}$ & $0.96(0.5-1.5)$ & $1.07(0.5-1.6)$ & 0.067 \\
\hline Physical functioning & $76.7(43.3-100)$ & $76.7(33.3-100)$ & 0.727 \\
\hline Role limitation - physical & $65.4(46.2-100)$ & $61.5(38.5-100)$ & 0.931 \\
\hline Bodily pain & $63.6(27.3-100)$ & $72.7(27.3-100)$ & 0.172 \\
\hline General health & $35(30-90)$ & $40(20-100)$ & 0.148 \\
\hline Vitality & $31.5(11.1-46.3)$ & $35.2(7.4-53.7)$ & 0.676 \\
\hline Social functioning & $50(20-100)$ & $60(20-100)$ & 0.537 \\
\hline $\begin{array}{l}\text { Role limitation - } \\
\text { emotional }\end{array}$ & $63.6(54.5-100)$ & $72.7(36.4-100)$ & 0.382 \\
\hline Mental health & $27.5(20-45)$ & $30(5-50)$ & 0.811 \\
\hline
\end{tabular}

* chi-square test, ${ }^{a}$ likelihood ratio test.

Table 1 The influence of stratified peritoneal Kt/V urea levels on SF-36 domains

\begin{tabular}{|c|c|c|c|c|c|c|c|c|c|c|c|c|c|c|c|c|}
\hline \multirow[t]{2}{*}{ SF-36 Domains } & \multicolumn{2}{|c|}{$\begin{array}{l}\text { Physical } \\
\text { functioning }\end{array}$} & \multicolumn{2}{|c|}{$\begin{array}{l}\text { Role limitation } \\
\text { - physical }\end{array}$} & \multicolumn{2}{|c|}{ Bodily pain } & \multicolumn{2}{|c|}{$\begin{array}{l}\text { General } \\
\text { health }\end{array}$} & \multicolumn{2}{|c|}{ Vitality } & \multicolumn{2}{|c|}{$\begin{array}{l}\text { Social } \\
\text { functioning }\end{array}$} & \multicolumn{2}{|c|}{$\begin{array}{l}\text { Role limitation } \\
\text { - emotional }\end{array}$} & \multicolumn{2}{|c|}{$\begin{array}{l}\text { Mental } \\
\text { health }\end{array}$} \\
\hline & $\bar{\beta}$ & $P$-value & $\bar{\beta}$ & $P$-value & $\bar{\beta}$ & $P$-value & $\bar{\beta}$ & $P$-value & $\bar{\beta}$ & $P$-value & $\bar{\beta}$ & $P$-value & $\bar{\beta}$ & $P$-value & $\bar{\beta}$ & $P$-value \\
\hline \multicolumn{17}{|l|}{$\begin{array}{l}\text { Peritoneal } \\
\text { Kt } / \mathrm{N} \text { urea }\end{array}$} \\
\hline$<1.2$ & 18.4 & 0.074 & 13.59 & 0.224 & 21.4 & 0.078 & 31.75 & 0.039 & 4.51 & 0.407 & -3.65 & 0.814 & 3.51 & 0.754 & 4.97 & 0.440 \\
\hline $1.2 \leqq K t / N<1.3$ & 27.62 & 0.015 & 27.27 & 0.027 & 5.46 & 0.676 & 37.49 & 0.025 & 8.10 & 0.174 & 6.47 & 0.702 & 14.95 & 0.224 & 11.18 & 0.113 \\
\hline $1.3 \leqq K t / N<1.4$ & 24.92 & 0.016 & 27.39 & 0.016 & 22.7 & 0.061 & 37.47 & 0.015 & 5.94 & 0.274 & 7.84 & 0.612 & 17.80 & 0.115 & 7.64 & 0.235 \\
\hline $1.4 \leqq K t / N<1.5$ & 20.71 & 0.047 & 24.73 & 0.030 & 25.04 & 0.042 & 27.91 & 0.070 & 9.94 & 0.073 & 11.77 & 0.452 & 10.81 & 0.341 & 10.64 & 0.104 \\
\hline $1.5 \leqq K t / N<1.6$ & 4.98 & 0.678 & 14.64 & 0.266 & 25.51 & 0.075 & 12.28 & 0.491 & -1.53 & 0.811 & -14.57 & 0.426 & 0.70 & 0.957 & 4.14 & 0.585 \\
\hline$\geqq 1.6$ & 20.91 & 0.028 & 18.96 & 0.067 & 19.83 & 0.076 & 43.74 & 0.002 & 10.59 & 0.037 & 6.66 & 0.641 & 12.33 & 0.235 & 7.55 & 0.204 \\
\hline
\end{tabular}

Statistical method: general linear model. 
Table 3 Baseline patient characteristics and SF-36 domains stratified by nPCR levels

\begin{tabular}{|c|c|c|c|}
\hline & $\mathrm{nPCR}$ & & \\
\hline & $<1.2(n=55)$ & $\geqq 1.2(n=22)$ & \\
\hline & $\overline{\text { Median (Range) }}$ & $\overline{\text { Median (Range) }}$ & $P$ \\
\hline Age (years) & $50.7(17.6-80.1)$ & $47.5(19.9-68.1)$ & 0.665 \\
\hline Gender, Male (n) & 5 & 33 & $0.780^{*}$ \\
\hline $\mathrm{DM}, \mathrm{n}(\%)$ & $2(18.2)$ & $20(30.3)$ & $0.392^{a}$ \\
\hline BMI & $24.4(16.4-35.2)$ & $20.6(14.4-25.8)$ & $<0.001$ \\
\hline $\begin{array}{l}\text { PD modality, } \\
\text { CAPD/APD (n) }\end{array}$ & $26 / 29$ & $16 / 6$ & $\underset{*}{<0.01}$ \\
\hline $\mathrm{Hb}(\mathrm{g} / \mathrm{dL})$ & $9(3-13)$ & $8.8(6-11)$ & 0.388 \\
\hline Albumin (g/dL) & $3.6(2.4-69)$ & $3.5(2.3-4.7)$ & 0.663 \\
\hline GPT (U/L) & $15(3-458)$ & $13.5(7-39)$ & 0.885 \\
\hline $\mathrm{Cr}(\mathrm{mg} / \mathrm{dL})$ & $11.5(5.4-21.7)$ & $12.6(3.9-20.1)$ & 0.564 \\
\hline hs-CRP (mg/L) & $3.33(0.2-199)$ & $7.86(0.5-65.2)$ & 0.299 \\
\hline Peritoneal Kt/N urea & $1.36(0.7-2.3)$ & $1.43(0.7-2.2)$ & 0.051 \\
\hline Residual renal Kt $N$ urea & $0.54(0-1.44)$ & $0.91(0-4.1)$ & 0.009 \\
\hline Total Kt/N urea & $1.92(1.1-3.0)$ & $2.34(1.8-4.8)$ & $<0.001$ \\
\hline $\begin{array}{l}\text { Peritoneal WCcr L/week } \\
1.73 \mathrm{~m}^{2}\end{array}$ & $35.3(20.9-55.2)$ & $36(10.9-52.1)$ & 0.973 \\
\hline 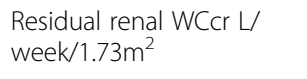 & $29(0-204.8)$ & $39.2(0-262.4)$ & 0.167 \\
\hline Total WCcr L/week/1.73m² & $68.8(31.4-226.7)$ & $84.4(45.6-348.4)$ & 0.007 \\
\hline $\mathrm{nPCR}$ & $0.96(0.5-1.2)$ & $1.35(1.2-1.6)$ & $<0.001$ \\
\hline Physical functioning & $76.7(33.3-100)$ & $78.3(36.7-100)$ & 0.612 \\
\hline Role limitation - physical & $61.5(38.5-100)$ & $65.4(46.2-100)$ & 0.769 \\
\hline Bodily pain & $72.7(27.3-100)$ & $72.7(27.3-100)$ & 0.659 \\
\hline General health & $40(20-100)$ & $35(20-90)$ & 0.416 \\
\hline Vitality & $35.2(7.4-51.9)$ & $34.3(11.1-44.4)$ & 1 \\
\hline Social functioning & $60(20-100)$ & $60(20-80)$ & 0.257 \\
\hline Role limitation - emotional & $68.2(36.4-100)$ & $68.2(45.5-100)$ & 1 \\
\hline Mental health & $30(10-50)$ & $30(5-45)$ & 0.938 \\
\hline
\end{tabular}

${ }^{*}$ chi-square test, ${ }^{a}$ likelihood ratio test.

scores for the SF-36 components did not differ between the groups stratified on the basis of cutoff values of 1.2 of $\mathrm{Kt} / \mathrm{V}$ urea or nPCR values (Tables 2 and 3).

The effects of baseline peritoneal kt/ $\mathrm{V}$ urea, renal WCcr, and $\mathrm{nPCR}$ values on the scores of the SF- 36 components after 6 months of PD

The patients who had baseline peritoneal Kt/V urea values of $<1.2$ showed an improvement in physical functioning and role limitations due to physical problems after 6 months of PD therapy. Patients who had baseline peritoneal Kt/V urea of $\geq 1.2$ showed improvement in general health, physical functioning, role limitation due to physical problems, and bodily pain (Table 4). Residual renal function of either $<40 \mathrm{~L} \cdot$ week $^{-1} \cdot 1.73 \mathrm{~m}^{-2}$ or $\geq 40$ $\mathrm{L} \cdot$ week $^{-1} \cdot 1.73 \mathrm{~m}^{-2}$ did not have an impact on SF-36 scores after 6 months of PD therapy. Deterioration was observed in all the components of the SF-36 after 6 months of PD therapy in patients with baseline nPCR values of $<1.2$ (Table 4 ).

\section{Discussion}

Small solute clearance measured by Kt/V urea is known to be one of the major determinants of dialysis adequacy. A growing body of evidence has suggested that a strong link exists between $\mathrm{Kt} / \mathrm{V}$ urea values and mortality rates in dialysis populations [10]. Therefore, to reduce the risk of mortality and improve dialysis adequacy, the total (renal + peritoneal) $\mathrm{Kt} / \mathrm{V}$ urea value should not be less than 1.7 for small solute removal, according to the guidelines of the Kidney Disease Outcomes Quality Initiative (KDOQI) and the International Society for Peritoneal Dialysis (ISPD) [11,12]. To reach this target, however, patients might experience adverse effects, including hernias (from the increased intra-abdominal pressure due to large volumes of dialysis solution), weight gain, and other metabolic consequences due to increased exposure to glucose. Furthermore, the increased amount of time needed to perform the exchanges is less acceptable to patients. These factors might not only adversely affect the willingness of the patients to continue PD therapy but also affect the QoL in incident PD patients. However, one study reported that a lower $\mathrm{Kt} / \mathrm{V}$ urea target was associated with a similar survival rate [13], leading us to consider what the impact of a lower $\mathrm{Kt} / \mathrm{V}$ urea target would be on QoL. In our study, we carefully stratified our patients on the basis of peritoneal $\mathrm{Kt} / \mathrm{V}$ urea values into 2 groups. Peritoneal Kt/V urea is the major component of total weekly Kt/V urea and is the critical component targeted in dialysis regimens. We found that patients with a peritoneal $\mathrm{Kt} / \mathrm{V}$ urea value of $>1.2$ experienced significant improvement in the QoL, especially in the domains of general health, physical function, and role limitation due to physical problems, at 6 months after the initiation of PD. Our results suggest that PD on its own is highly beneficial in improving the QoL in patients whose peritoneal $\mathrm{Kt} / \mathrm{V}$ urea value is above 1.2. This result implies that some domains of the QoL could be improved after 6 months of PD therapy with a lower peritoneal $\mathrm{Kt} / \mathrm{V}$ urea target. However, the influence of a lower peritoneal $\mathrm{Kt} / \mathrm{V}$ urea value on longterm QoL and patient survival needs to be further investigated. Our study also suggests that it might not be necessary to pursue a higher adequacy target at the expense of QoL in the early phase of PD initiation. By not pursuing a higher adequacy target, the early discontinuation of incident PD patients observed occasionally can be avoided. 
Table 4 Multivariate analysis using the general linear model to assess the difference of influence on the SF-36 between one month and six months following peritoneal dialysis therapy

\begin{tabular}{|c|c|c|c|c|c|c|c|c|c|c|c|c|}
\hline & \multicolumn{3}{|c|}{ Physical functioning } & \multicolumn{3}{|c|}{ Role limitation -physical } & \multicolumn{3}{|c|}{ Bodily pain } & \multicolumn{3}{|c|}{ General health } \\
\hline & $\boldsymbol{\beta}$ & (CI) & $P$ & $\boldsymbol{\beta}$ & (Cl) & $P$ & $\boldsymbol{\beta}$ & (Cl) & $p$ & $\beta$ & (Cl) & $p$ \\
\hline Age & -0.309 & $(-0.67-0.05)$ & 0.09 & -0.357 & $(-0.75-0.03)$ & 0.07 & -0.24 & $(-0.66-0.18)$ & 0.262 & -0.266 & $(-0.79-0.26)$ & 0.32 \\
\hline \multicolumn{13}{|c|}{ Peritoneal Kt/N } \\
\hline$<1.2$ & 26.971 & $(3.81-50.14)$ & 0.023 & 34.326 & $(9.21-59.44)$ & 0.008 & 25.518 & $(-1.88-52.91)$ & 0.067 & 30.703 & $(-3.53-64.94)$ & 0.078 \\
\hline$\geqq 1.2$ & 21.166 & $(1.64-40.70)$ & 0.034 & 26.026 & $(4.85-47.20)$ & 0.017 & 23.245 & $(-0.15-46.34)$ & 0.049 & 33.373 & $(4.51-62.24)$ & 0.024 \\
\hline \multicolumn{13}{|c|}{ Residual renal WCCr } \\
\hline$<40$ & 2.824 & $(-7.24-12.89)$ & 0.578 & -4.666 & $(-15.58-6.25)$ & 0.397 & -3.383 & $(-15.29-8.52)$ & 0.573 & 10.481 & $(-4.40-25.36)$ & 0.164 \\
\hline$\geqq 40$ & 0 & - & & 0 & - & & 0 & - & & 0 & - & \\
\hline \multicolumn{13}{|l|}{$\mathrm{nPCR}$} \\
\hline$<1.2$ & -5.645 & $(-16.25-4.96)$ & 0.292 & -3.325 & $(-14.82-8.17)$ & 0.566 & -0.083 & $(-12.62-12.46)$ & 0.99 & -9.164 & $(-24.83-6.51)$ & 0.247 \\
\hline \multirow[t]{3}{*}{$\geqq 1.2$} & 0 & - & & 0 & - & & 0 & - & & 0 & - & \\
\hline & \multicolumn{3}{|c|}{ Vitality } & \multicolumn{3}{|c|}{ Social functioning } & \multicolumn{3}{|c|}{ Role limitation- emotional } & \multicolumn{3}{|c|}{ Mental health } \\
\hline & $\boldsymbol{\beta}$ & (CI) & $p$ & $\boldsymbol{\beta}$ & (Cl) & $P$ & $\beta$ & (Cl) & $P$ & $\beta$ & (Cl) & $p$ \\
\hline Age & -0.089 & $(-0.28-0.10)$ & 0.346 & 0.107 & $(-0.42-0.63)$ & 0.687 & -0.154 & $(-0.55-0.24)$ & 0.437 & -0.142 & $(-0.37-0.08)$ & 0.206 \\
\hline \multicolumn{13}{|c|}{ Peritoneal Kt/N } \\
\hline$<1.2$ & 11.974 & $(-0.21-24.16)$ & 0.054 & 6.724 & $(-27.39-40.83)$ & 0.695 & 19.574 & $(-5.92-45.07)$ & 0.13 & 11.234 & $(-3.18-25.65)$ & 0.125 \\
\hline$\geqq 1.2$ & 9.276 & $(-1.0-19.55)$ & 0.076 & 2.663 & $(-26.09-31.42)$ & 0.854 & 15.297 & $(-6.20-36.79)$ & 0.16 & 8.402 & $(-3.75-20.55)$ & 0.172 \\
\hline \multicolumn{13}{|c|}{ Residual renal WCCr } \\
\hline$<40$ & 2.936 & $(-2.36-8.23)$ & 0.273 & 13.906 & $(-0.92-28.73)$ & 0.066 & -0.775 & $(-11.86-10.31)$ & 0.889 & 0.949 & $(-5.32-7.21)$ & 0.763 \\
\hline$\geqq 40$ & 0 & - & & 0 & - & & 0 & - & & 0 & - & \\
\hline \multicolumn{13}{|l|}{$\mathrm{nPCR}$} \\
\hline$<1.2$ & -6.484 & $(-12.06--0.91)$ & 0.023 & -13.46 & $(-29.07-2.15)$ & 0.09 & -6.162 & $(-17.83-5.51)$ & 0.296 & -2.398 & $(-9.0-4.20)$ & 0.471 \\
\hline$\geqq 1.2$ & 0 & - & & 0 & - & & 0 & - & & 0 & - & \\
\hline
\end{tabular}

Multivariate analysis:

The nPCR value, also called protein equivalent of nitrogen appearance (PNA), can be used to assess dietary protein intake in patients who are in a steady state. It has also been adopted as a reference value to adjust dialysis prescription. When poor nutrition (e.g., nPCR $<0.8$ $\mathrm{g} \cdot \mathrm{kg}^{-1} \cdot \mathrm{day}^{-1}$ ) or inadequate dialysis (e.g., Kt/V urea $<1.2$ ) is apparent, the dialysis prescription has to be adjusted to meet the clinical situation. Moreover, to ascertain whether a significant change has occurred may require several months of $n P C R$ and Kt/V urea level monitoring. A previous study has demonstrated that mortality rates increased in dialysis patients with nPCR values of less than $0.8 \mathrm{~g} \cdot \mathrm{kg}^{-1} \cdot \mathrm{day}^{-1}$ or greater than $1.4 \mathrm{~g} \cdot \mathrm{kg}^{-1} \cdot \mathrm{day}^{-1}$ [14]. Among patients with nPCR levels between $0.8 \mathrm{~g} \cdot \mathrm{kg}^{-1} \cdot \mathrm{day}^{-1}$ and 1.2 $\mathrm{g} \cdot \mathrm{kg}^{-1} \cdot \mathrm{day}^{-1}$, an increase or decrease in protein intake during the first 6 months was associated with an increase or decrease in the survival rate over the subsequent 18 months, respectively. Thus, reduced survival is associated with an initially low nPCR and decreased protein intake over time. In the present study, patients with baseline $\mathrm{nPCR}$ values of $>1.2 \mathrm{~g} \cdot \mathrm{kg}^{-1} \cdot \mathrm{day}^{-1}$ had higher renal $\mathrm{Kt} / \mathrm{V}$ urea values and higher weekly Ccr values than those with nPCR values of $<1.2 \mathrm{~g} \cdot \mathrm{kg}^{-1} \cdot \mathrm{day}^{-1}$. Patients with $\mathrm{nPCR}$ values greater than $1.2 \mathrm{~g} \cdot \mathrm{kg}^{-1} \cdot$ day $^{-1}$ showed improvement in SF-36 domain scores after 6 months of PD therapy. In contrast, patients with nPCR values of $<1.2 \mathrm{~g} \cdot \mathrm{kg}^{-1}$. day ${ }^{-1}$ showed a decrease in SF-36 domain scores after 6 months of PD therapy. The exact mechanism by which residual renal function improves the QoL in subjects with nPCR values of $>1.2 \mathrm{~g} \cdot \mathrm{kg}^{-1} \cdot$ day $^{-1}$ needs to be further investigated. However, this finding implicates nutritional status as key factor in QoL improvement with PD initiation. Therefore, it is essential to devise a strategy to increase the nutritional status primarily in the early phase of PD commencement.

In the past few years, some investigators have focused on the reasons for the early discontinuation PD therapy by patients. The NECOSAD study demonstrated that the psychosocial effect of PD therapy was a one of the major reasons why patients discontinued therapy in the first 3 months [15]. Another study from a single PD center also showed that psychosocial effects were a major cause of early discontinuation of therapy in the 
first 6 months of PD therapy [16]. However, one study has shown that the measures of social relationships and physical health of PD patients did not significantly change during the early and late phases of treatment [17]. Furthermore, it has been found in one study that emotional defensiveness affects the physical and mental components of HRQoL in patients undergoing dialysis [18]. In that study, the incident PD patients needed an adjustment period to adapt to their uncertain psychological status; the complex, time-consuming PD exchange procedure affected their response to $\mathrm{PD}$ therapy. This finding suggests that psychological effects must not be ignored in the management of patients undergoing dialysis. Our study clearly showed that PD could improve the QoL, as measured by the SF-36 instrument, after 6 months of therapy. However, we found that a lower peritoneal $\mathrm{Kt} / \mathrm{V}$ urea value further contributed to a remarkable improvement in the QoL. We assume that a more satisfactory PD prescription might reduce the psychosocial burden on incident PD patients, even though it would attain a lower adequacy index. This approach did not sacrifice the QoL in incident PD patients, as per our results.

\section{Conclusion}

In summary, the QoL in incident PD patients can be improved with a low of $\mathrm{Kt} / \mathrm{V}$ urea value in the PD prescription. Moreover, lower nPCR levels will offset the benefits of PD initiation on the QoL improvement. Additionally, a few aspects of the QoL domains in the SF-36 could be further improved in 6-month PD therapy in the cohort with low Kt/V urea levels. The results could guide medical staff in individualizing the medical plan for incident PD patients. We conclude that a stepwise PD program is essential for incident PD patients. This gradual approach to PD prescription need not be at the expense of QoL in incident PD patients.

\footnotetext{
Abbreviations

APD: Automated Peritoneal Dialysis; CAPD: Continuous Ambulatory Peritoneal Dialysis; Ccr: Creatinine Clearance; CHEQ: Choices Health Experiences Questionnaire; Cl: Confidence Interval; CKD: Chronic Kidney Disease; ESRD: End-stage Renal Disease; hs-CRP: High-sensitivity C-reactive Protein; kDQOL: Kidney Disease Quality of Life; nPCR: Normalized Protein Catabolic Rate; PD: Peritoneal Dialysis; PET: Peritoneal Equilibrium Test; PNA: Protein Equivalent of Nitrogen Appearance; QoL: Quality of Life; SF-36: Short Form Health Survey-36; WHOQOL: World Health Organization Quality of Life Survey; WCcr: Weekly Creatinine Clearance.
}

\section{Competing interests}

The authors declare that they have no competing interests.

\section{Acknowledgments}

The authors acknowledge the support given by Chang Gung Memorial Hospital CMRP (grant number CMRPG880091) to help conduct this study.

\section{Authors' contributions}

$J B C$ and $K K L$ collected and interpreted the data, critically reviewed the manuscript, and drafted the manuscript after incorporating some revisions. YJS conceived the research question, interpreted the data, and critically reviewed the manuscript. WCL, BCC, CCK, and YCW participated in the acquisition and interpretation of data, revised the manuscript critically, and performed the statistical analyses. CHW and EL assisted with data collection, interpreted the data, and were involved in the drafting of the manuscript. TCC and SCL conceived, designed, and coordinated the study and commented on the final draft. All authors have read and approved the final manuscript.

\section{Author details}

All authors worked at the Division of Nephrology, Kaohsiung Chang Gung Memorial Hospital and Chang Gung University College of Medicine, Kaohsiung, Taiwan

Received: 19 December 2011 Accepted: 14 June 2012

Published: 14 June 2012

\section{References}

1. Kalantar-Zadeh $\mathrm{K}$, Unruh M: Health related quality of life in patients with chronic kidney disease. Int Urol Nephrol 2005, 37:367-78.

2. Martinez-Castelao A, Gorriz JL, Garcia-Lopez F, Lopez-Revuelta K, De Alvaro F, Cruzado JM: Perceived health-related quality of life and comorbidity in diabetic patients starting dialysis (CALVIDIA study). J Nephrol 2004, 17:544-51.

3. Chow FY, Briganti EM, Kerr PG, Chadban SJ, Zimmet PZ, Atkins RC: Healthrelated quality of life in Australian adults with renal insufficiency: a population-based study. Am J Kidney Dis 2003, 41:596-604.

4. Morton AR, Meers C, Singer MA, et al: Quantity of dialysis: quality of lifewhat is the relationship? ASAIO J 1996, 42:M713-7.

5. Merkus MP, Jager KJ, Dekker FW, De Haan RJ, Boeschoten EW, Krediet RT: Quality of life over time in dialysis: the Netherlands Cooperative Study on the Adequacy of Dialysis. NECOSAD Study Group. Kidney Int 1999, 56:720-8.

6. Chen YC, Hung KY, Kao TW, Tsai TJ, Chen WY: Relationship between dialysis adequacy and quality of life in long-term peritoneal dialysis patients. Perit Dial Int 2000, 20:534-40.

7. Kalantar-Zadeh K, Kopple JD, Block G, Humphreys MH: Association among SF36 quality of life measures and nutrition, hospitalization, and mortality in hemodialysis. J Am Soc Nephrol 2001, 12:2797-806.

8. Spiegel BM, Melmed G, Robbins S, Esrailian E: Biomarkers and healthrelated quality of life in end-stage renal disease: a systematic review. Clin J Am Soc Nephrol 2008, 3:1759-68.

9. Peng YS, Chiang CK, Hung KY, et al: Comparison of self-reported healthrelated quality of life between Taiwan hemodialysis and peritoneal dialysis patients: a multi-center collaborative study. Qual Life Res 2011, 20:399-405.

10. Churchill DN, Thorpe KE, Nolph KD, Keshaviah PR, Oreopoulos DG, Page D: Increased peritoneal membrane transport is associated with decreased patient and technique survival for continuous peritoneal dialysis patients. The Canada-USA (CANUSA) Peritoneal Dialysis Study Group. J Am Soc Nephrol 1998, 9:1285-92.

11. Clinical practice guidelines for peritoneal dialysis adequacy. Am J Kidney Dis 2006, 48(Suppl 1):S98-129. doi:10.1053/j.ajkd.2006.04.006.

12. Lo WK, Bargman JM, Burkart J, et al: Guideline on targets for solute and fluid removal in adult patients on chronic peritoneal dialysis. Perit Dial Int 2006, 26:520-2.

13. Lo WK, Ho YW, Li CS, et al: Effect of Kt/V on survival and clinical outcome in CAPD patients in a randomized prospective study. Kidney Int 2003, 64:649-56.

14. Shinaberger CS, Kilpatrick RD, Regidor $\mathrm{DL}$, et al: Longitudinal associations between dietary protein intake and survival in hemodialysis patients. Am J Kidney Dis 2006, 48:37-49.

15. Kolesnyk I, Dekker FW, Boeschoten EW, Krediet RT: Time-dependent reasons for peritoneal dialysis technique failure and mortality. Perit Dial Int 2010, 30:170-7.

16. Descoeudres B, Koller MT, Garzoni D, et al: Contribution of early failure to outcome on peritoneal dialysis. Perit Dial Int 2008, 28:259-67. 
17. Ginieri-Coccossis M, Theofilou P, Synodinou C, Tomaras V, Soldatos C: Quality of life, mental health and health beliefs in hemodialysis and peritoneal dialysis patients: investigating differences in early and later years of current treatment. BMC Nephrol 2008, 9:14.

18. Anna Kaltsouda, Petros Skapinakis, Dimitrios Damigos, Margarita Ikonomou, Rigas Kalaitzidis, Venetsanos Mavreas, Siamopoulos Kostas C: Defensive coping and health-related quality of life in chronic kidney disease: a cross-sectional study. BMC Nephrol 2011, 12:28.

doi:10.1186/1471-2369-13-39

Cite this article as: Chen et al:: Relationship between $\mathrm{Kt} / \mathrm{V}$ urea-based dialysis adequacy and nutritional status and their effect on the components of the quality of life in incident peritoneal dialysis patients. BMC Nephrology 2012 13:39.

\section{Submit your next manuscript to BioMed Central and take full advantage of:}

- Convenient online submission

- Thorough peer review

- No space constraints or color figure charges

- Immediate publication on acceptance

- Inclusion in PubMed, CAS, Scopus and Google Scholar

- Research which is freely available for redistribution 